\title{
A self-potential investigation of submarine massive sulfides: Palinuro Seamount, Tyrrhenian Sea
}

Roxana Safipour ${ }^{1}$, Sebastian Hölz ${ }^{2}$, Jesse Halbach ${ }^{1}$, Marion Jegen ${ }^{2}$, Sven

Petersen $^{2}$, Andrei Swidinsky ${ }^{1}$

1. Colorado School of Mines

Department of Geophysics

1500 Illinois St., Golden, CO, 80401, USA.

E-mail: rsafipou@mines.edu

2. GEOMAR, Helmholtz Centre for Ocean Research

Geodynamics Department

Wischhofstr. 1-3, 24148 Kiel, Germany

Contact Details:

Roxana Safipour

rsafipou@mines.edu

Running Head: Marine self-potential method 


\section{ABSTRACT}

The self-potential (SP) method detects naturally occurring electric fields which may be produced by electrically conductive mineral deposits such as massive sulfides. Recently, there has been increasing interest in applying this method in a marine environment to explore for seafloor massive sulfide (SMS) deposits which may contain economic resources of base and precious metals. While SMS sites that are associated with active venting and are not buried under sediment cover are known to produce an SP signal, the effectiveness of the method at detecting inactive and sediment-covered deposits remained an outstanding question. We built an instrument capable of recording SP data in a marine setting. We carried out a test of the instrument at the Palinuro Seamount in the Tyrrhenian Sea. Palinuro is one of only a few known sites containing an SMS occurrence which is buried under sediment and not associated with active hydrothermal venting, although diffuse seepage of hydrothermal fluids is known to occur at the site. Elevated electric field strengths recorded in and near the site of previously drilled massive sulfide samples are on the order of $1-3 \mathrm{mV} / \mathrm{m}$. A second zone of high field strengths was detected by us to the north of the drilling area where gravity coring later confirmed the existence of massive sulfides. Our observations indicate that an SP signal can be observed at the site of SMS mineralization even when the mineralized zone is shallowly buried and active hydrothermal venting is not present. These observations could aid in the planning of future marine research expeditions which use the SP method in the exploration of seafloor massive sulfides.

\section{INTRODUCTION}

In recent years, interest has increased in exploring for massive sulfide deposits on the seafloor, as evidence suggests these deposits may provide an economic resource of base and precious metals (Lipton, 2008; Hannington et al., 2011). Seafloor massive sulfide (SMS) mineralization typically occurs at marine plate boundaries such as mid-ocean ridges, 
volcanic arcs, and back-arc basins, where hydrothermal fluids rise from deep in the crust, mix with cold seawater, and precipitate minerals on or below the seafloor (Hannington et al., 2005). 237 SMS deposits are currently known to exist throughout the world's oceans (Beaulieu et al., 2015; Monecke et al., 2016). Most of these sites are small and economically not of interest. However, the economic potential of occurrences that are buried underneath a blanket of sediments is likely much higher (Petersen et al., 2016).

Magnetic and electromagnetic methods have been applied in the search for SMS deposits (Wolfgram et al., 1986; Cairns et al., 1996; Kowalczyk, 2008; Tao et al., 2013; Caratori Tontini et al., 2014; Ligi et al., 2014; Szitkar et al., 2015). A less commonly used method is the self-potential (SP) method, which looks for naturally occurring anomalies in electrical potential which can arise from buried conductive bodies (e.g., massive sulfides, graphite shear zones) (Sato and Mooney, 1960) or from streaming potentials caused by fluid flow (e.g., groundwater) (Revil and Jardani, 2013). The SP method has been shown to work in marine environments, where both graphite and massive sulfide bodies have been detected by marine SP systems (Brewitt-Taylor, 1975; Corwin, 1976; Von Herzen et al., 1996; Heinson et al., 1999, 2005; Beltenev et al., 2007, 2009; Cherkashov et al., 2010; Shilov et al., 2012; Cherkashev et al., 2013). In a few cases, massive sulfides at the Mid-Atlantic Ridge were found to produce an SP anomaly even where no hydrothermal activity was present (Cherkashev et al., 2013). However, prior to our study, the SP method had not been tested over a hydrothermally inactive SMS site which is buried under sediment.

Marine SP data have typically been acquired via electrodes towed in-line behind a ship (e.g., Heinson et al. 1999; Cherkashev et al. 2013). Rather than measuring the electrical potential with respect to a remote reference point as is commonly done on land, for logistical reasons these systems measure the electric field strength, which is the spatial derivative of the electrical potential. Most systems tested in the past only measured the horizontal electric field component aligned with the towing direction of the ship, although 
Von Herzen et al. (1996) measured the vertical electric field in an experiment at the TAG hydrothermal mound. The horizontal component of the electric field perpendicular to the towing direction has typically not been measured.

We built and tested a new marine SP system (Figure 1A) which was mounted onto a larger carrier system for EM measurements. A data logger and two pairs of Ag-AgCl electrodes manufactured by Silvion were attached onto a lower fiberglass-reinforced plastic frame $(4.3 \mathrm{~m} \mathrm{x} 4.3 \mathrm{~m})$, which allowed us to measure both components of the horizontal electrical field. The frame was suspended $15 \mathrm{~m}$ beneath a second frame, which held the electronics for active EM experiments, which are not considered in the scope of this paper. The entire system can be raised or lowered with a winch, and an altimeter was used to measure the height of the system above the seafloor. For positioning we used a Posidonia USBL system (IXSea).

The field area chosen for this study is the Palinuro Seamount in the southeastern Tyrrhenian Sea, located at $39.5^{\circ} \mathrm{N}, 14.7^{\circ} \mathrm{E}$ (Figure 1B). Massive sulfide samples were collected first from the western part of Palinuro by Minniti and Bonavia (1984) and later by Petersen et al. (2014) a few km to the east in our study area. Gravity, magnetic, sonar backscatter reflectivity, and detailed bathymetric data have been collected over this area (Caratori Tontini et al., 2014; Ligi et al., 2014; Petersen et al., 2014; Szitkar et al., 2015), but electrical and electromagnetic methods had not been attempted prior to this study. Diffuse seepage of low-temperature hydrothermal fluids has been detected at Palinuro (Lupton et al., 2011; Thiel et al., 2012), but no active chimneys have been discovered. Shallow drilling carried out by Petersen et al. (2014) indicates that the massive sulfide mineralization is typically buried under up to several meters of volcaniclastic sediment, making this a good test site for the exploration of buried deposits which lack black-smoker type hydrothermal activity.

\section{DATA COLLECTION AND PROCESSING}


The system was tested at Palinuro during the research cruise POS509 (R/V Poseidon, Feb. 15 - Mar. 3, 2017). SP data were collected over two days: on the first day the frame was towed along seven N-S profiles and on the second day along twelve E-W profiles over the study area. The system was towed at a very low speed of 0.4 knots $(0.2$ $\mathrm{m} / \mathrm{s}$ ) while the cable length was adjusted to keep the frame between 5-10 $\mathrm{m}$ above the seafloor as determined by the on-board altimeter. At the beginning and end of each profile, the system was raised to a height of $100 \mathrm{~m}$ above the seafloor and kept at this height for 5 minutes to measure the background noise without any geologic signal from the seafloor. These periods were used as control points to correct for temporal electrode drift.

Voltages were recorded by the two pairs of electrodes every 1 second. The voltages measured by the electrode pairs were converted to electric fields, $E_{1}$ and $E_{2}$, by dividing by the separation distance of the electrodes $(4.3 \mathrm{~m})$. Tilt sensors attached to the frame show that pitch and roll were on average $1.2^{\circ}\left( \pm 4.0^{\circ} @ 2 \sigma\right)$ and $2.4^{\circ}\left( \pm 4.4^{\circ} @ 2 \sigma\right)$, respectively; since the tilt angles were small at all times, $E_{1}$ and $E_{2}$ are effectively horizontal. The data were smoothed using a moving average with a window size of $60 \mathrm{~s}$ to remove oscillations in the data caused by the transmitter from the EM experiment which was being carried out simultaneously. A temporal electrode-drift curve was calculated by fitting a $2^{\text {nd }}$ order polynomial through the control points when the system was high in the water column, and consequently removed from the data. When the ship winch was moving the system up or down in the water column, the vertical movement of the cable produced electrical noise; thus the data during vertical instrument movement were trimmed. For the E-W profiles, an overall shift was apparent in the data from the eastward-towed lines versus the westward-towed lines, with the eastward-towed lines showing fields on average $222 \mu \mathrm{V} / \mathrm{m}$ higher than the westward-towed lines for $E_{1}$ and $397 \mu \mathrm{V} / \mathrm{m}$ higher for $E_{2}$. While we are unsure of the exact cause of this shift, we theorize that it may be related to the interaction of the towing cable with the Earth's magnetic field; this theory is supported by the fact that no apparent shift is seen between the northward-towed and southward-towed 
lines on the N-S profiles when the system is being towed mostly parallel to the Earth's magnetic field. To remove this effect, the data from the eastward towed and westward towed lines were leveled to each other by subtracting half the average difference from the eastward towed lines and adding half the average difference to the westward towed lines for each electrode pair. The data processing steps are summarized in Figure 2.

Since the system is free to rotate horizontally about the winch cable, $E_{1}$ and $E_{2}$ represent arbitrary orthogonal directions at any given time. We calculated the magnitude of the total horizontal field, $E_{h}$, as $\sqrt{E_{1}^{2}+E_{2}^{2}}$, which is independent of the orientation of the system (Figure 3). In addition, heading data from an on-board compass with a sampling rate of $\sim 1.6 \mathrm{~Hz}$ were used to trigonometrically calculate the northward and eastward components of the horizontal electric field, referred to as $E_{x}$ and $E_{y}$, respectively.

\section{DATA ANALYSIS}

Several areas at Palinuro were found to have elevated $E_{h}$ values on the order of 1-3 $\mathrm{mV} / \mathrm{m}$, which is an order of magnitude greater than the background $E_{h}$ values of a few hundred $\mu \mathrm{V} / \mathrm{m}$ (Figure 3). Most of the areas of high $E_{h}$ values can be spatially correlated with massive sulfide samples collected at Palinuro. Previous shallow drilling has recovered 11 core samples containing massive sulfides in the northwestern part of the crater (Petersen et al., 2014). The location of these drill core samples, indicated by the green bounding box in Figure 3, corresponds spatially with high $E_{h}$ values on both the N-S and E-W profiles. On the N-S profiles, high $E_{h}$ values are seen to occur both to the NW and SE of the drilling site, which is consistent with our working hypothesis that a possible NW-SE trending fault structure can be interpreted from the bathymetry at the drilling site. In addition, high $E_{h}$ values are observed $\sim 200 \mathrm{~m}$ to the north of the drilling site on both the N-S and E-W profiles, located outside of the crater hosting the drilled mineralization. After observing these anomalies in the SP data, a gravity coring device was used to collect samples of seafloor sediment in the area of the anomalies. A gravity-corer sample indicated by the green asterisk on Figure 3, located between high $E_{h}$ values on the N-W profiles 
and proximal to elevated $E_{h}$ values on an E-W profile, contained a thick layer $(>1 \mathrm{~m})$ of sediments bearing massive sulfides starting at $180 \mathrm{~cm}$ below the seafloor. Two additional zones of high $E_{h}$ values in the SW part of the field area observed on the E-W profiles correspond with areas which have not been sampled at this time.

The spatial correlation between high $E_{h}$ values and massive sulfide sampling suggests that the high $E_{h}$ values are produced by a geologic source. The source of these electric fields could be the presence of highly conductive massive sulfide bodies spanning a vertical redox potential gradient in the seafloor, consistent with the explanation suggested by Sato and Mooney (1960) for SP anomalies on land. Alternatively, while active high-temperature venting of hydrothermal fluids is not present at Palinuro, the electric fields could result from the diffuse seepage of hydrothermal fluids through the seafloor in the mineralized zone or by geochemical reactions between the sulfides and the porewaters.

Further evidence that these electric fields result from a geologic source is obtained by examining $E_{x}$ and $E_{y}$ (Figure 4 ). We consider an SP anomaly produced by a massive sulfide occurrence; for a vertical conductor, such anomalies typically consist of a local low in the electrical potential (Sato and Mooney, 1960) (Figure 4A). A system is towed from west to east across the potential low and measures the electric field components $E_{x}$ and $E_{y}$, which are the negative spatial derivatives $-d / d x$ and $-d / d y$ of the electrical potential. If the system passes to the north of the "bullseye" of the potential low, $E_{x}$ will be negative at all times, with a minimum occurring when the system passes due north of the bullseye. Conversely, $E_{y}$ will be positive before passing due north of the bullseye, zero at the point due north of the bullseye, and negative after passing due north of the bullseye. Indeed, this pattern is observed in the data in several places on the E-W profiles; one example is shown in detail in Figure 4B. On the N-S profiles, we expect to see the opposite pattern, with a sign change occurring in $E_{x}$ but not in $E_{y}$. This pattern is also observed in several places in the N-S profiles; one example is shown in detail in Figure 4C. In this example, two zero 
crossings occur in $E_{x}$, suggesting that the system was towed across two local lows in the electrical potential located close together. The presence of these patterns in the $E_{x}$ and $E_{y}$ data suggests that the elevated electric field measurements are the result of local lows in the electrical potential, which are likely produced by geology or diffuse hydrothermal fluid seepage in the seafloor. In addition, this suggests that with densely sampled data, analysis of the relative strengths of the $E_{x}$ and $E_{y}$ components could be used to vector in on the bullseye of the electrical potential, which would be useful from an exploration standpoint.

\section{CONCLUSIONS}

We performed a marine self-potential (SP) experiment which recorded both horizontal components of the electric field. The system was tested over an area of known sediment-covered massive sulfide mineralization with only diffuse low-temperature hydrothermal fluid seepage at the Palinuro Seamount in the southeastern Tyrrhenian Sea. Zones of elevated horizontal electric field strengths were observed in close proximity to locations where massive sulfide cores have been collected from the seafloor. These elevated field strengths may result from the presence of electrically conductive massive sulfide bodies in the seafloor, or from the seepage of hydrothermal fluids through the seafloor in the mineralized zone. Past experiments have demonstrated that seafloor massive sulfide occurrences can produce natural electric fields even when no hydrothermal activity is present; however, this study represents the first test of an SP system over a seafloor massive sulfide occurrence which is buried beneath sediment cover. The magnitudes of the elevated field strengths observed at Palinuro are on the order of $1-3 \mathrm{mV} / \mathrm{m}$. These field strengths are comparable to the SP anomalies observed over massive sulfide occurrences which are not buried, where anomalies of a few $\mathrm{mV} / \mathrm{m}$ in the electric field have also been observed. Patterns observed in the northward and eastward components of the electric field are indicative of local lows in the electrical potential, which is consistent with the typical SP signal produced by massive sulfide deposits on land. Our experiment at Palinuro 
demonstrates that the marine SP method is a useful exploration tool at shallowly buried seafloor massive sulfide occurrences with only diffuse hydrothermal activity.

\section{ACKNOWLEDGMENTS}

This project received funding from GEOMAR, the Colorado School of Mines, and the European Union as part of the Blue Mining project: FP7 Grant No. 604500. We wish to thank our reviewers for their help in improving the manuscript, and in particular Reviewer 2 for the suggestion that the baseline shifts observed in the E-W profiles resulted from the interaction of the towing cable with the Earth's magnetic field.

\section{REFERENCES}

Beaulieu, S., E. Baker, and C. German, 2015, Where are the undiscovered hydrothermal vents on oceanic spreading ridges?: Deep Sea Research Part II, 121.

Beltenev, V., I. Ivanov, I. Rozhdestvenskaya, G. Cherkashov, T. Stepanova, V. Shilov, M. Davydov, A. Laiba, V. Kaylio, E. Narkevsky, A. Pertsev, I. Dobretzova, A. Gustaytis, Y. Popova, Y. Amplieva, C. Evrard, L. Moskalev, and A. Gebruk, 2009, New data about hydrothermal fields on the Mid-Atlantic Ridge between $11^{\circ}-14^{\circ} \mathrm{N}$ : 32nd cruise of $\mathrm{R} / \mathrm{V}$ Professor Logatchev: InterRidge News, 18, 13-17.

Beltenev, V., V. Ivanov, I. Rozhdestvenskaya, G. Cherkashov, T. Stepanova, V. Shilov, A. Pertsev, M. Davydov, I. Egorov, I. Melekestseva, E. Narkevsky, and V. Ignatov, 2007, A new hydrothermal field at $13^{\circ} 30^{\prime} \mathrm{N}$ on the Mid-Atlantic Ridge: InterRidge News, 16, $9-10$.

Brewitt-Taylor, C., 1975, Self-potential prospecting in the deep oceans: Geology, 3, 541-543.

Cairns, G., R. Evans, and R. Edwards, 1996, A time-domain electromagnetic survey of the TAG hydrothermal mound: Geophysical Research Letters, 23, 3455-3458. 
Caratori Tontini, F., G. Bortoluzzi, C. Carmisciano, L. Cocchi, C. de Ronde, M. Ligi, and F. Muccini, 2014, Near-bottom magnetic signatures of submarine hydrothermal systems at Marsili and Palinuro Volcanoes, Southern Tyrrhenian Sea, Italy: Economic Geology, 109, 2119-2128.

Cherkashev, G., V. Ivanov, V. Beltenev, L. Lazareva, I. Rozhdestvenskaya, M. Samovarov, I. Poroshina, M. Sergeev, T. Stepanova, I. Dobretsova, and V. Kuznetsov, 2013, Massive sulfide ores of the northern equatorial Mid-Atlantic Ridge: Oceanology, 53, 607-619.

Cherkashov, G., I. Poroshina, T. Stepanova, V. Ivanov, V. Beltenev, L. Lazareva, I.

Rozhdestvenskaya, M. Samovarov, V. Shilov, G. Glasby, Y. Fouquet, and V. Kuznetsov, 2010, Seafloor massive sulfides from the northern equatorial Mid-Atlantic Ridge: New discoveries and perspectives: Marine Georesources \& Geotechnology, 28, 222-239.

Corwin, R., 1976, Offshore use of the self-potential method: Geophysical Prospecting, 24, $79-90$.

Hannington, M., C. de Ronde, and S. Petersen, 2005, Sea-floor tectonics and submarine hydrothermal systems: Economic Geology, 100th Anniversary Volume, 111-141.

Hannington, M., J. Jamieson, T. Monecke, S. Petersen, and S. Beaulieu, 2011, The abundance of seafloor massive sulfide deposits: Geology, 39, 1155-1158.

Heinson, G., A. White, S. Constable, and K. Key, 1999, Marine self potential exploration: Exploration Geophysics, 30, 1-4.

Heinson, G., A. White, D. Robinson, and N. Fathianpour, 2005, Marine self-potential gradient exploration of the continental margin: Geophysics, 70, G109-G118.

Hölz, S., M. Jegen, S. Petersen, and M. Hannington, 2015, How to find buried and inactive seafloor massive sulfides using transient electromagnetics - A case study from the Palinuro Seamount in the Tyrrhenian Sea: Underwater Mining Institute Conference, Tampa Bay, FL, USA, 1-8.

Kowalczyk, P., 2008, Geophysical prelude to first exploitation of submarine massive sulphides: First Break, 26, 99-106. 
Ligi, M., L. Cocchi, G. Bortoluzzi, F. D’Oriano, F. Muccini, F. Tontini, C. de Ronde, and C. Carmisciano, 2014, Mapping of seafloor hydrothermally altered rocks using geophysical methods: Marsili and Palinuro seamounts, southern Tyrrhenian Sea: Economic Geology, 109, 2103-2117.

Lipton, I., 2008, Mineral resource estimate Solwara 1 project Bismarck Sea Papua New Guinea for Nautilus Minerals Inc: Technical report, Technical Report Canadian NI43-101 form F1.

Lupton, J., C. de Ronde, M. Sprovieri, E. Baker, P. Bruno, F. Italiano, S. Walker, K. Faure, M. Leybourne, K. Britten, , and R. Greene, 2011, Active hydrothermal discharge on the submarine Aeolian Arc: Journal of Geophysical Research, 116, B02102.

Minniti, M., and F. Bonavia, 1984, Copper-ore grade mineralization discovered in a seamount in the Tyrrhenian Sea (Mediterranean): Is the mineralization related to porphyry-coppers or to base metal lodes?: Marine Geology, 59, 271-282.

Monecke, T., S. Petersen, M. Hannington, H. Grant, and I. Samson, 2016, The minor element endowment of modern sea-floor massive sulfides and comparison with deposits hosted in ancient volcanic successions: Reviews in Economic Geology, 18, 245-306.

Petersen, S., A. Krätschell, N. Augustin, J. Jamieson, J. Hein, and M. Hannington, 2016, News from the seabed - Geological characteristics and resource potential of deep-sea mineral resources: Marine Policy, 70, 175-187.

Petersen, S., T. Monecke, A. Westhues, M. Hannington, J. Gemmell, R. Sharpe, M. Peters, H. Strauss, K. Lackschewitz, N. Augustin, H. Gibson, and R. Kleeberg, 2014, Drilling shallow-water massive sulfides at the Palinuro volcanic complex, Aeolian Island Arc, Italy: Economic Geology, 109, 2129-2157.

Revil, A., and A. Jardani, 2013, The self-potential method: Theory and applications in environmental geosciences: Cambridge University Press.

Sato, M., and H. Mooney, 1960, The electrochemical mechanism of sulfide self-potentials: Geophysics, 25, 226-249. 
Shilov, V., V. Beltenev, V. Ivanov, G. Cherkashev, I. Rozhdestvenskaya, I. Gablina, I. Dobretsova, E. Narkevskii, A. Gustaitis, and V. Kuznetsov, 2012, New hydrothermal ore fields in the Mid-Atlantic Ridge: Zenith-Victoria $\left(20^{\circ} 08^{\prime} \mathrm{N}\right)$ and Petersburg $\left(19^{\circ} 52^{\prime} \mathrm{N}\right)$ : Doklady Earth Sciences, 442, 63-69.

Szitkar, F., S. Petersen, F. Caratori Tontini, and L. Cocchi, 2015, High-resolution magnetics reveal the deep structure of a volcanic-arc-related basalt-hosted hydrothermal site (Palinuro, Tyrrhenian Sea): Geochemistry, Geophysics, Geosystems, 16, 1950-1961.

Tao, C., W. Xiong, Z. Xi, X. Deng, and Y. Xu, 2013, The investigations of South Atlantic Ridge $13.2^{\circ} \mathrm{S}$ hydrothermal area: Acta Oceanologica Sinica, 32, 68-74.

Thiel, V., M. Hugler, M. Blumel, H. Baumann, A. Gartner, R. Schmaljohann, H. Strauss, D. Garbe-Schonberg, S. Petersen, D. Cowart, C. Fisher, and J. Imhoff, 2012, Widespread occurrence of two carbon fixation pathways in tubeworm endosymbionts: lessons from hydrothermal vent associated tubeworms from the Mediterranean sea: Frontiers in Microbiology, 3, 1-20.

Von Herzen, R., J. Kirklin, and K. Becker, 1996, Geoelectrical measurements at the TAG hydrothermal mound: Geophysical Research Letters, 23, 3451-3454.

Wolfgram, P. A., R. Edwards, L. Law, and M. N. Bone, 1986, Polymetalic sulfide exploration on the deep seafloor: The feasability of the MINI-MOSES experiment: Geophysics, 51, 1808-1818. 


\section{FIGURE CAPTIONS}

Figure 1: A) Photo of the marine SP system. A 4.3 by $4.3 \mathrm{~m}$ square frame holding two pairs of electrodes is horizontally suspended $15 \mathrm{~m}$ below a cube containing the system electronics, which is in turn suspended from a cable to a winch on board the ship. B) A regional map showing the location of the Palinuro Seamount.

Figure 2: The data processing steps: 1 . Smoothing with a $60-$ s moving average to remove oscillations from the EM system transmitter. 2. Removal of temporal electrode drift and trimming of times when the system was high in the water column. 3. Removal of the apparent shift between the eastward-towed transects and westward-towed transects and trimming of times during vertical winch movement. A) The full time series of $E_{2}$ for the E-W profiles. B) A close-up of a zone of anomalously high field strength, indicated by the pink bar labeled "1" in part A of this figure and also by location number 1 in Figure 3.

Figure 3: Magnitude of the horizontal electric field, $E_{h}$. The area containing previously drilled massive sulfide samples is indicated by the green rectangle. A gravity core sediment sample containing a thick layer of massive sulfides is indicated by the green asterisk. Bathymetry is indicated by the black contours. A) Full survey area. B) A close-up of the zone around the massive sulfide samples, indicated by the black square in part A.

Figure 4: A) A theoretical depiction of the expected $-d / d y$ and $-d / d x$ derivatives measured by a system towed across a local low in a potential field. B) A 90-m segment of $E_{x}$ and $E_{y}$ data from the E-W profiles indicated by location number 1 in Figure 3. C) A 90-m segment of $E_{x}$ and $E_{y}$ data from the N-S profiles indicated by location number 2 in Figure 3 . 


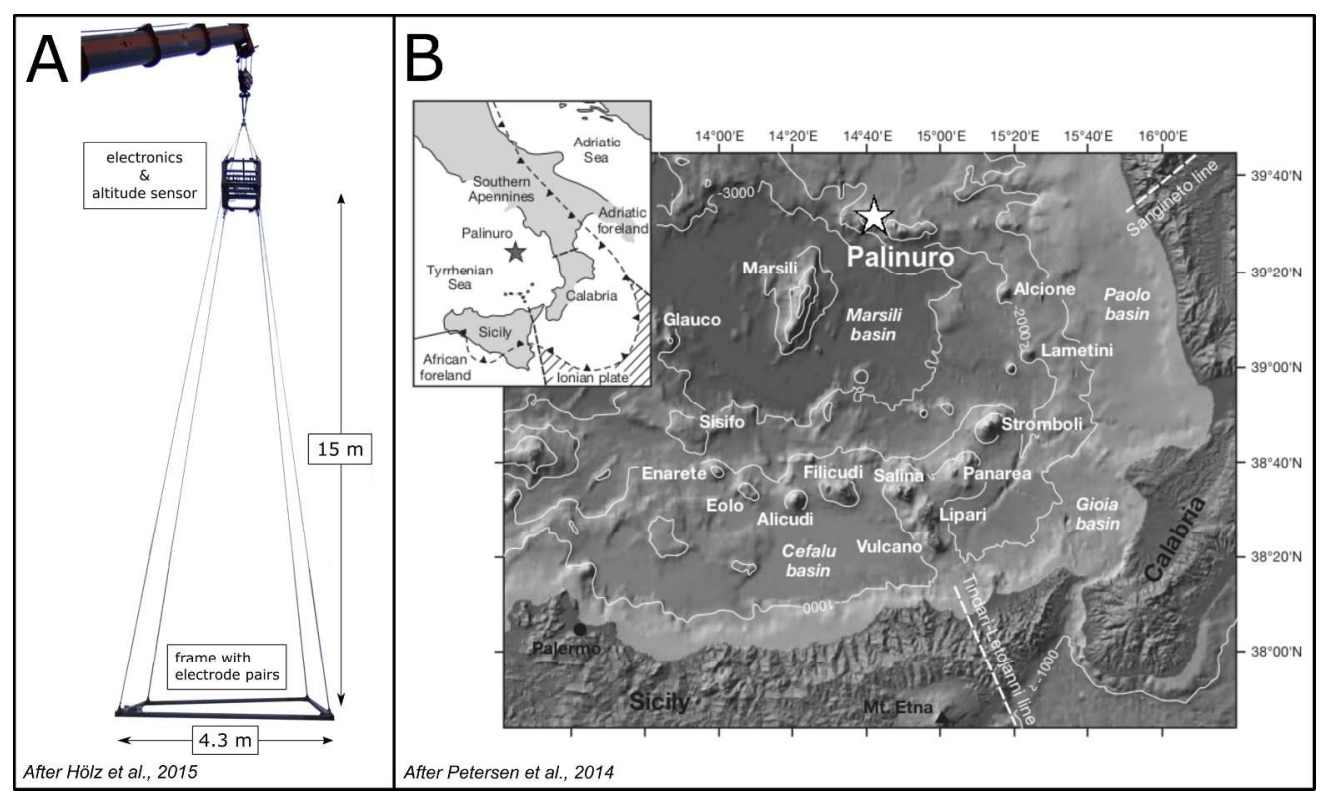

Figure 1: A) Photo of the marine SP system. A 4.3 by $4.3 \mathrm{~m}$ square frame holding two pairs of electrodes is horizontally suspended $15 \mathrm{~m}$ below a cube containing the system electronics, which is in turn suspended from a cable to a winch on board the ship. B) A regional map showing the location of the Palinuro Seamount.

$476 \times 284 \mathrm{~mm}(144 \times 144 \mathrm{DPI})$ 


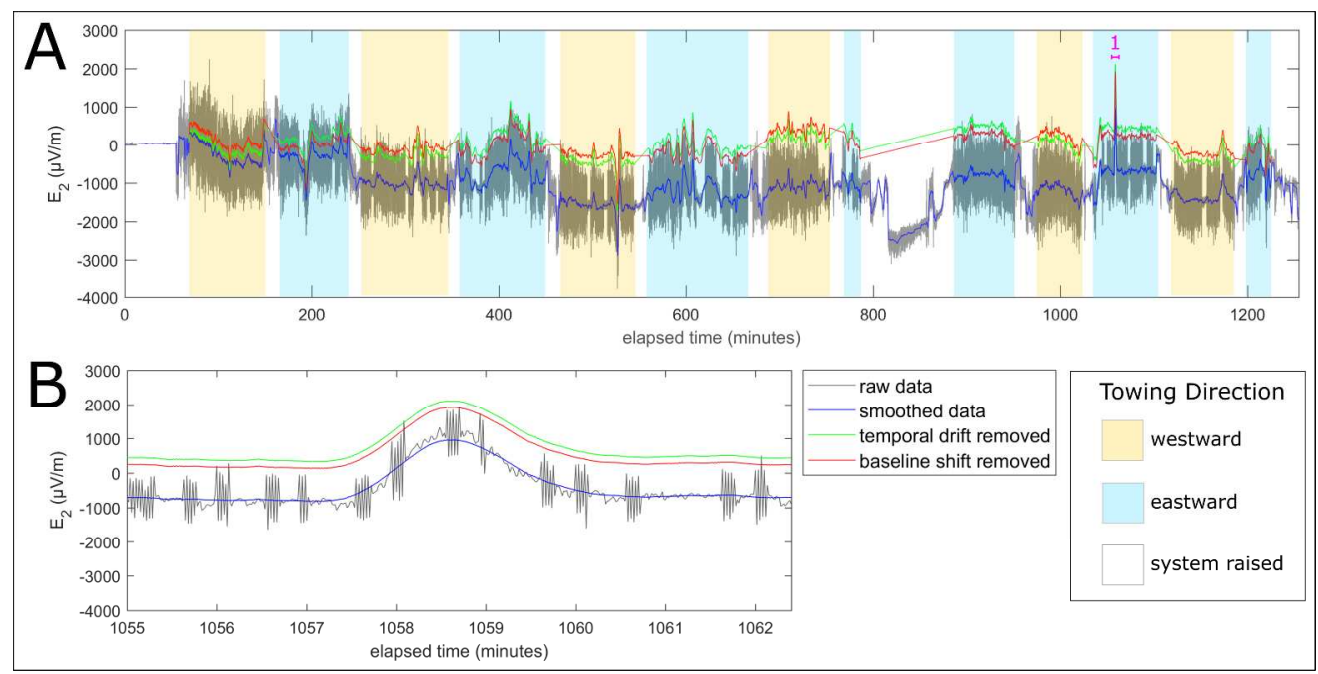

Figure 2: The data processing steps: 1 . Smoothing with a $60 \mathrm{~s}$ moving average to remove oscillations from the EM system transmitter. 2. Removal of temporal electrode drift and trimming of times when the system was high in the water column. 3. Removal of the apparent shift between the eastward-towed transects and westward-towed transects and trimming of times during vertical winch movement. A) The full time series of $E_{2}$ for the E-W profiles. B) A close-up of a zone of anomalously high field strength, indicated by the pink bar labeled " 1 " in part $A$ of this figure and also by location number 1 in Figure 3.

$599 \times 303 \mathrm{~mm}(144 \times 144$ DPI) 


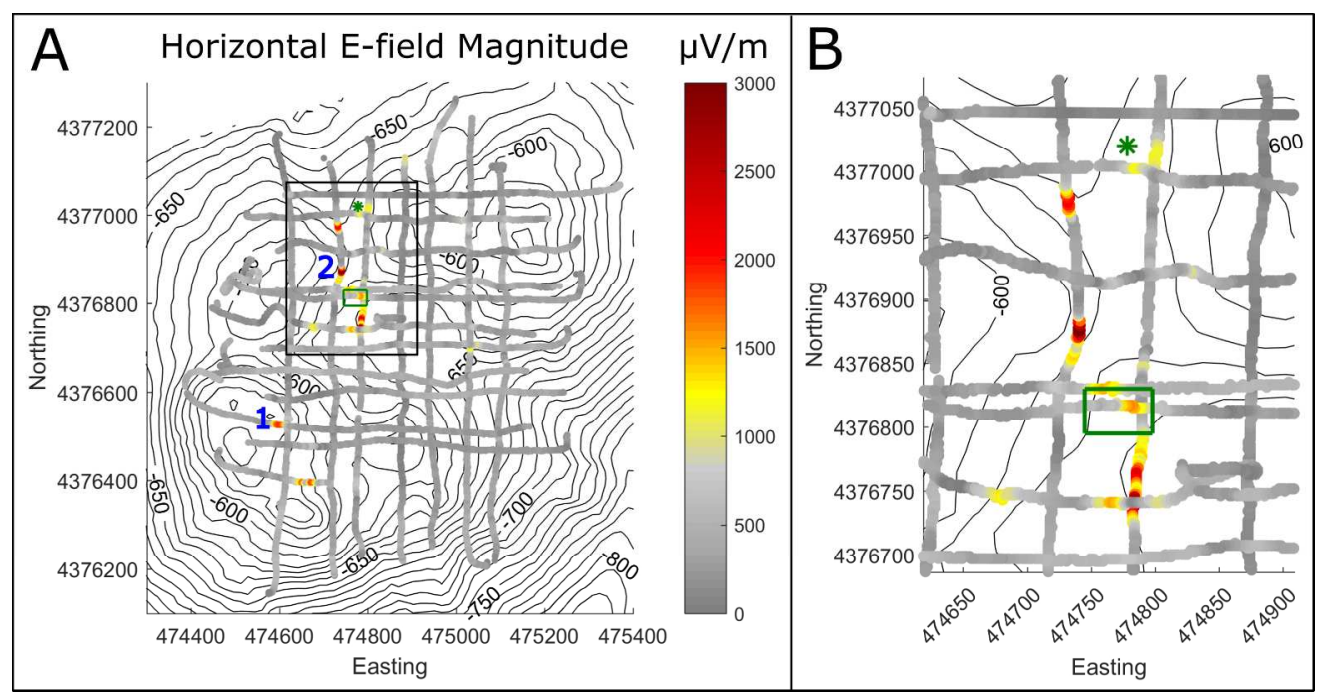

Figure 3: Magnitude of the horizontal electric field, $E_{h}$. The area containing previously drilled massive sulfide samples is indicated by the green rectangle. A gravity core sediment sample containing a thick layer of massive sulfides is indicated by the green asterisk. Bathymetry is indicated by the black contours. A) Full survey area. B) A close-up of the zone around the massive sulfide samples, indicated by the black square in part A.

$464 \times 241 \mathrm{~mm}(144 \times 144$ DPI $)$ 


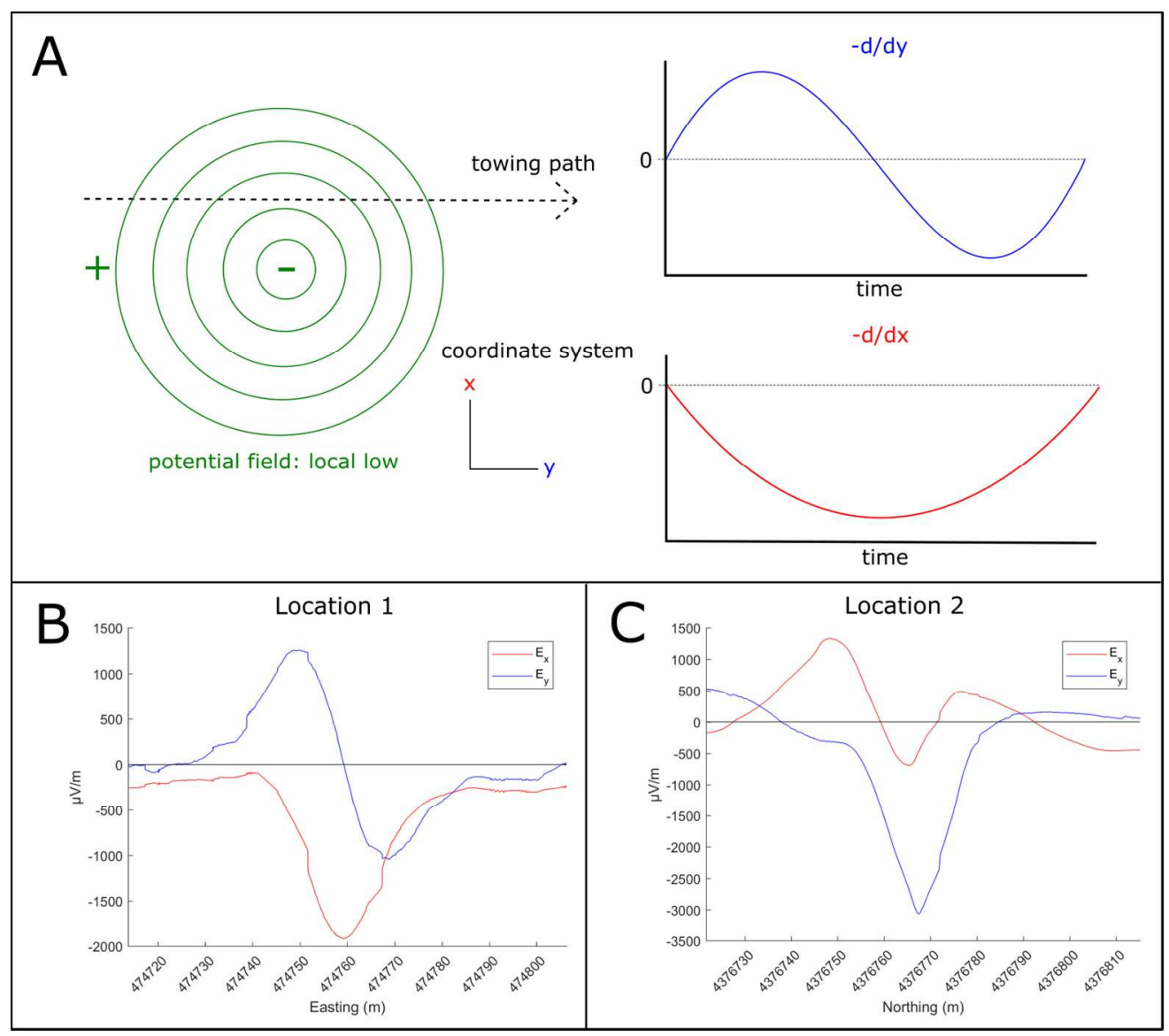

Figure 4: A) A theoretical depiction of the expected $-d / d x$ and $-d / d y$ derivatives measured by a system towed across a local low in a potential field. B) A $90 \mathrm{~m}$ segment of $E_{x}$ and $E_{y}$ data from an E-W profile indicated by location number 1 in Figure 3. C) A $90 \mathrm{~m}$ segment of $E_{x}$ and $E_{y}$ data from a N-S profile indicated by location number 2 in Figure 3.

$291 \times 258 \mathrm{~mm}(144 \times 144$ DPI $)$ 